\title{
7. Conditions and processes of policy innovation in multilevel governance
}

The empirical studies presented in the previous two chapters report on policymaking in different institutional settings of multilevel governance, with different governance mechanisms operating under different conditions. Nevertheless, they are not meant to allow a systematic comparative research designed to prove or test a theory. They should only illustrate the relevance of the approach suggested in Chapter 4 and provide some empirical evidence for the theoretical conclusions drawn from the state of research.

It is particularly important to note that the cases do not allow for the evaluation of multilevel systems, where power is dispersed across jurisdictions, in comparison to unitary political systems which enable a concentration of power. As mentioned in the introduction, this book should explain that complex political systems can not only adjust to a turbulent environment, but can also cope with difficult problems by policy innovation. It cannot prove that multilevel governance promises more effective policies than 'centripetal' democracies (Gerring and Hacker 2008). However, it makes the case for a more differentiated evaluation of complex governments and multilevel governance than is suggested by quantitative comparative research based on institutionalist approaches or veto player theory. As Liesbet Hooghe and Gary Marks convincingly argued, multilevel governance arises in response to an increasing territorial differentiation and functional interdependence of societies. Therefore, it has to be taken as a fact and as result of a transformation of political authority, irrespective of the form of the governments involved in multilevel governance. Hence the challenge is to find appropriate institutions and procedures of coordination, in view of the societal conditions of politics.

This chapter starts by summarizing the fundamental developments in society which impact on politics in multilevel governance. It then discusses how a multilevel system and processes of governance can be shaped to increase the feasibility of policy change or innovation. This discussion will not lead to a recommendation of an appropriate 'model' of multilevel governance. As follows from the theories outlined in Chapters 2, 3 and 4 and as the case studies illustrate, innovative policymaking cannot be guaranteed by institutions or procedures. Much depends on how actors strategically cope with institutional constraints and political conflicts and how they shape processes. Therefore, 
the following reasoning implies an actor-centred approach to multilevel governance which takes societal and institutional conditions as crucial, but as conditions to which actors can adapt or which they can influence.

\section{SOCIETAL CONDITIONS}

With their 'postfunctionalist approach' to explain the rise of multilevel governance, Liesbet Hooghe and Gary Marks (2009; Hooghe et al. 2016a, 2016b) highlighted three fundamental conditions which can be traced back to changes in society: the functional interdependence of the causes and consequences of political decisions across levels; the political demands for autonomy expressed by communities; and the polarization of politics. The first condition results from growing transactions and external effects across borders of territorially organized states and their sub-units. Claims for autonomy reflect the loyalty of citizens to a political community. Political polarization results from cleavages in a society which find expression in party systems. In principle, trans-border movement of people, interchange of goods, capital or services and externalities have always been an issue for states, and governments have tried to control these processes, with different means and varying effects and costs. Likewise, politics has always implied the formation of communities as well as their integration or disintegration. And polarization has always threatened political stability, whenever fundamental conflicts have divided societies and, in consequence, shaped party systems and party politics. Controlling mobility and externalities across borders, ensuring the loyalty of citizens in order to integrate communities, and structuring politics in party systems are processes which shape state formation and which also drive the transformation of states and the evolution of multilevel governance (Bartolini 2005; Rokkan 1999). And yet, conditions for multilevel coordination have changed significantly.

First, waves of democratization in nation states and the globalization of markets since the 19th century dramatically reduced the power of national, regional and local governments to use borders as an instrument of control. What started as a liberalization of societies and advancement of equality has meanwhile revealed its ambivalent consequences. On the one hand, citizens in democratic political systems are free to move around, although immigration into nation states is still regulated by national law. Constraining mobility through border control would be against the fundamental principles of liberty. Global trade and communication have increased the prosperity of citizens, corporations and governments, while guaranteeing fair and liberal market economies has become a matter of international politics and trade treaties. On the other hand, mobility and global trade have caused negative externalities. They threaten the social balance of welfare states, the stability of the economy, the security of citizens and communities, and the sustainability of the global 
ecological system. As responses by governments to migration and their efforts to mitigate the COVID-19 pandemic show, controlling state borders is still an option for politics in nation states, but it is an option that contradicts basic legal and political principles. In consequence, coordinating policies in multilevel governance is inevitable and appears as 'functional'. However, it requires coping with the ambivalences of freedom and political regulation, which become particularly challenging as multilevel governance has turned out as increasingly 'politicized', that is, a matter of disputes and contestation.

The contestation of functional justifications for multilevel governance is grist for the mill of movements or parties claiming autonomy for their community. Such claims are raised by ethnic groups which feel excluded from multilevel governance and demand acknowledgement in politics and participation in policymaking. In contrast, national communities which define their identity by a distinct language or a particular political history, and perceive themselves as a minority in a larger society, call for sovereignty, at least on specific matters, and thus reject external influence, in particular by upper-level authorities. Consequently, they refuse to participate in multilevel coordination. Minority nationalism is not only driven by identities, but also by interests, and therefore it evolves under specific economic conditions. While for a long time it was predominantly observable in peripheries of states or federations (Hechter 1975), it appears meanwhile mainly in prosperous regions which defend their resources or welfare against external competitors, immigration or requests for redistribution (Keating 2004). This kind of economic nationalism is also on the rise in international relations of states. In consequence, policymaking in multilevel governance is burdened by territorial conflicts among governments and, accordingly, the risk of deadlock in the management of interdependence has increased. In reaction to these divides, states prefer exclusive agreements to multilateral coordination, particular communities or nation states opt out from intergovernmental agreements or they insist on minority rights. In this case, structures of multilevel governance tend to become asymmetric.

As indicated, minority nationalism can also be caused by economic disparities, and the nationalism in prospering regions challenges multilevel governance in total. Yet growing economic and social disparities (Milanović 2011; Piketty 2020) also affect policymaking in multilevel governance. Within states, local and regional governments facing deficient fiscal capacities call for distributive justice by fiscal equalization. In international politics, governments representing underdeveloped countries tend to link substantial policy issues with demands for financial compensations, which, for instance, emerged as an important topic in international climate negotiations. Such package deals are feasible in joint-decision making or cooperation and help to avoid deadlock. However, as they result from distributive bargaining, significant change or 
policy innovation is unlikely under these conditions in which negotiating governments try to limit redistributive effects burdening their taxpayers.

Changes in party politics have reinforced territorial conflicts. In Western democracies, scholars have observed a new territorial cleavage leading to a transformation of party systems. Post-materialist values and ecological issues are now finding greater resonance in party politics, and these issues concern problems at different scales. Mainstream parties representing the basic consensus on the welfare state are increasingly challenged by parties supporting the globalization of markets and parties claiming to defend national or regional resources or speaking for those who are left behind in globalization. This new cleavage and the rise of territorial politics impacts particularly on European integration (Kriesi et al. 2012). The multilevel political system of the EU, which until the 1990s was based on a 'permissive consensus' within the member states, has turned into a matter of contestation, if not political polarization. Within nation states, regionalist or ethnic parties have gained ground in many Western democracies as well as in Asian countries. Although these parties are often integrated in consensual politics and multilevel governance (Breen and Thomas 2021), and although they increase diversity which can stimulate innovation, predominating value conflicts and contrasting constitutional ideas can increase the risk of deadlock in policymaking. In general, it is an open question whether this new divide obstructs governance or whether parties find a compromise on an appropriate division of power between levels. Be that as it may, the politicization of territorial conflicts makes policy coordination more difficult. Instead of advancing intended innovations, significant change can have disruptive effects and can contribute to the disintegration of multilevel governance.

A final condition of multilevel governance has so far been widely neglected in research. One cause for interdependence across boundaries of jurisdictions is digitalization and the development of the World Wide Web. By improving and accelerating communication and by reducing transaction costs, digitalization has led to an expansion of international trade and has dramatically transformed global financial markets. States, regions and local communities increasingly rely on a digital infrastructure to control public utilities, connecting administrative organizations, linking administrations to citizens and enabling interactions with other parts of the world. In consequence, they also have to face new risks which require national and transnational regulation and coordination. Digital communication also changes policymaking in multilevel governance, in different ways. Regulation of the internet is partly privatized and partly in the hands of governments or international authorities. Thus, a unique kind of multilevel governance has emerged. Moreover, actors in traditional forms of multilevel governance profit from the new options to communicate. Yet the type of communication has changed, with effects that 
are hardly understood still. Presumably, the intensity and speed of information exchange have increased and have improved the management of crises, as can be observed in the COVID-19 pandemic. However, digital communication lacks the potential of personal relations to build trust, which is essential to solve conflicts. Given the state of research (Chadwick 2020; Roy 2021), we can only speculate about the positive and negative impacts of digitalization on multilevel governance, but the consequences for policymaking and policy change should not be underestimated.

To conclude: While interdependence of policies across levels of governments and beyond nation states has led to new structures and processes of multilevel governance, coordination of policies has become more and more difficult under changing societal conditions. These conditions vary by state and world region, but also by policy fields. Nevertheless, it seems that functional reasons for multilevel governance are increasingly disputed, and that the intensity of conflicts has generally increased. For this reason, searching for appropriate institutions and processes of coordination has gained in importance.

\section{INSTITUTIONAL CONDITIONS}

Institutional conditions of multilevel governance can be discussed under three categories: the division of powers, the institutions of governments involved in multilevel governance, and the linkages between multilevel and domestic (intragovernmental) politics. Beyond these institutional 'dimensions', the rigidity or flexibility of institutionalization affects the opportunities for policy and institutional change.

The division of power determines the degree of interdependence to be managed across jurisdictions and the modes of coordination available to cope with external effects and redistributive problems. Other things being equal, the larger the territory of the jurisdiction and the wider the portfolio of public policies falling under the responsibility of an authority, the less the need for cross-border coordination. Irrespective of the territorial structure of jurisdiction, centralization of powers reduces interdependence (or internalizes external effects), while decentralization has the opposite effect. However, the larger the jurisdiction, the greater the diversity of the territories it encompasses, and the more policies of the centre have to be differentiated according to geographical, economic, social and cultural aspects. Therefore, with the increasing size of a polity, powers should be divided between levels of government in order to avoid overload of the central government.

Yet this is a very abstract and general argument. Scholars working on multilevel or federal systems have long debated the advantages or disadvantages of a particular division of power. They found reasons speaking for centrali- 
zation or decentralization but, in the end, different reasons have to be taken into account and pondered, and the result of this assessment depends on the political aims pursued by governments (Treisman 2007). The same applies to the discussion about separation or sharing of power, the former meaning that authorities at each level can unilaterally decide on policies within their domain, and the latter requiring joint policymaking. Power separation is often preferred, because democracy presumes autonomy of governments and because executives take full and clear responsibility for their decisions towards parliaments or citizens. However, it is less the degree of autonomy characterizing these different ways to divide powers but rather the modes of multilevel governance enabled by them that is crucial for effectiveness or legitimacy of governance. Whereas shared rule privileges intergovernmental cooperation, often by excluding the exit options of individual governments, separation of power tends towards governance in the shadow of hierarchy or decentralized competition, but does not rule out voluntary cooperation. In reality, neither shared rule nor self-rule determines the modes of coordination.

In terms of the division of power, multilevel governance is typically characterized by a functional differentiation. Decisions on standards, goals and rules are to a considerable extent centralized, whereas their implementation is decentralized. Redistributive policies affecting the whole polity call for central decision, whereas the provision of services and public utilities needs to be decentralized, depending on their territorial scale. This functional division reflects the complexity of problems surfacing in contemporary societies, and it causes interdependence of policies made at different levels. Powers are divided according to functions, because policies have to address general and specific aspects of societal problems. To cope with these problems effectively, divided functions have to be fulfilled in a coordinated way. Therefore, this kind of division of power structures policymaking in multilevel governance. The typical division of functions in multilevel governance finds reflection, in turn, in the dynamic interplay between agenda setting, the definition of principles or rules, and the discourses about experiences and best practices at the global or European level on the one hand, and binding decisions and implementation of principles, rules or policy recommendations at the national, regional and local level on the other. This interplay can be observed in energy and climate policy. In pure redistributive policies like fiscal equalization, functional division is revealed in the responsibility of central governments to guarantee a fiscal balance across territories in which regional or local governments provide public goods and services.

The second institutional dimension concerns the form of governments and domestic politics within jurisdictions. Executives interacting in multilevel governance are subject to the rules and norms of their government. In autocracies, political leaders can ignore such constraints, but this does not mean 
that autocratic rule is compatible with multilevel governance. When policies are coordinated by intergovernmental agreements, the hands of delegates of autocratic political leaders are more strongly tied in negotiations than the hands of executives representing democratic governments. In governance by competition, autocrats are under pressure to profit from multilevel governance, because they depend on output legitimacy. At the same time, they tend to insulate their government from performance evaluations even if they claim ostensibly to accept standards of good governance.

In democratic governments, executives are accountable to, and have to take into account the will of, parliaments or public opinion. In parliamentary democracies, their hands can be tied by mandates defined by the majority in parliament, and they may be confronted by a critical opposition when they make concessions in intergovernmental negotiations or adjust policies in response to interjurisdictional competition. As research on comparative federalism has revealed, tensions between multilevel governance and democracy are particularly intense in parliamentary democracies, either because the discretion of executives is constrained by the will of the parliament or because a parliament can veto policies or blame the executive in public for decisions resulting from multilevel governance (Lehmbruch 2000; Sharmann 1990). In democracies where the powers of the executive and legislature are separated, the former has a stronger position in multilevel governance and is more inclined to respond to public opinion, which rarely determines the policy preferences of the executive. However, the differences should not be overestimated (Benz and Sonnicksen 2021). In general, multilevel governance and democratic governments operate according to distinct rules and procedures and include different actor constellations, and the resulting policy processes interfere and cause mutual constraints and tensions.

How these linkages between multilevel governance and democratic governments affect policymaking in multilevel governance largely depends on the degree of institutionalization, or, to put it in another way, the flexibility of institutions for managing the tensions. Highly rigid constellations usually result from the combination of a parliamentary system with institutionalized power sharing requiring joint decisions. Even under these conditions, strategic actors may find ways to escape the Joint-Decision Trap, although usually at the cost of ineffective policies and democratic deficits (Scharpf 1988). Yet executive-parliament relations do not necessarily determine the policy preferences of actors in multilevel governance. In majoritarian democracies, the executive can often rely on the majority of one party and is not necessarily bound to coalition agreements. In consensus democracies, the executive may be able to settle compromises with varying parties if it needs support for decisions in multilevel governance. The risk that executives dominate negotiations on intergovernmental agreements committing their government can be reduced 
if individual governments have the right to opt out. Informal preparation of joint decisions in inter-administrative relations can moderate the influence of party competition on policymaking in multilevel governance and thus partially separate executive governance and democratic politics, which can be harmonized in a process of mutual adjustment.

Regardless of the patterns of democracy or autocracy, considerable flexibility can be achieved by variation in patterns of multilevel coordination. This applies in particular to political systems where powers are separated between levels and where multilevel governance rests on emergent norms rather than formal rules. Cooperation is voluntary per se, and cooperation in the shadow of hierarchy implies that, in cases of disagreement, a central authority decides. Yardstick competition and policy transfer are highly open for various outcomes. Yet even if powers are shared, regular meetings or informal processes of cooperative or competitive interaction among executives, civil servants, party representatives, members of parliament or private actors can add to institutionalized joint-decision making. Intergovernmental councils, for instance, are established organizations which have gained in importance in federations due to the increasing interdependence of policies. They imply no binding commitments for joint decisions but can prepare these decisions. Founded on agreements among participating governments, members can renegotiate or reinterpret the rules of coordination whenever it appears appropriate. In all these patterns of multilevel governance, communicative processes complement strategic politics, and the outcomes of these processes serve as reasons to justify policies in democratic politics, even if these reasons, like ideas, can be used as 'discursive weapons' in the political process (Béland 2009: 702).

In general, institutionalization of multilevel governance is lower in international governance than within states or federations (Westerwinter et al. 2021). Still, negotiations among heads of governments and international agreements can significantly constrain democratic politics, and similar constraints result from competition among states. Flexibility of multilevel governance is clearly higher the more levels are linked. Under these conditions, policy processes can 'bypass' an intermediary government in order to avoid formal procedures and to open arenas for communicative processes. The US federal government, for instance, provided grants directly to cities after President Johnson had initiated the 'war on poverty' (Robertson 2012: 132). The EU Commission directly addressed and communicated with governments of regions or cities when implementing its structural policy. Local and regional governments, on the other hand, contact European or international organizations when pursuing their interests or search for assistance (Tatham 2010).

This flexibility makes multilevel governance work and allows actors to accommodate effective governance with democratic legitimacy. In addition, it creates opportunities for innovative policies. Policy innovation, however, 
results from processes, and processes in different arenas need to be arranged in a way that reduces constraints inherent in complex multilevel governance and takes advantage of the flexibility of loosely coupled arenas.

\section{PROCESSES}

Significant policy change, which is intended by policymakers, rarely results from an abrupt and rapid revision of established practices. Inventions need time to mature, and when they crop up they often remain an issue in discussions among experts, and many also disappear for some time in the long lists of proposals rejected in political processes, before they are rediscovered. In multilevel governance they may be implemented in one or a few jurisdictions or may be identified as best practices by external review boards or authorities, without inducing policy change on a larger scale. As convincingly explained by theories of policy or institutional change (see Chapter 3), inventions turn into innovations after a balance of power within a policy regime or among competing policy communities has become unstable, after a gradual evolution of policies along an existing path has proved ineffective and unsustainable, and after a crisis of governance, protests or threats of disintegration have created a critical situation, after ideas justifying policies have been contested, or after external events have triggered change. While these processes drive dynamics of policymaking, new ideas or a revision of a predominating policy paradigm channel policy change in an intended direction. In energy and climate policy, the politics of the liberalization of markets and the paradigm of economic growth was challenged by new knowledge on the causes and possible effects of climate change. Reforms of fiscal equalization, which went beyond a gradual adjustment of existing legislation, followed explicitly stated principles of distributive justice and effective provision of public goods and services.

All these causes and conditions can also initiate change in multilevel governance. In these structures, however, particular processes are set in motion which can either constrain or enable and drive policy innovation. The case studies presented in the preceding chapters reveal that these processes differ according to institutional conditions and the type of policy, but that flexible, loosely coupled or 'redundant' structures of multilevel governance provide enabling conditions for actors to shape the policy process in a way that makes change feasible.

Multilevel governance in climate policy reveals flexible and inflexible structures, if we consider that the whole governance system affects all levels, from global to local politics. The international climate policy regime, which has emerged over the last few decades, is based on intergovernmental politics among state governments but meanwhile includes an internally differentiated forum for discursive processes including executives, experts and NGOs that 
have continuously influenced the negotiations of national governments. To an increasing extent, these 'epistemic communities' have been connected to regional and local policymaking. They have inspired discussions, policy agendas and politics on these sub-national levels, although international treaties commit national governments in the first place. Local policy innovations have been stimulated by supralocal policy networks or best practice contests organized by the EU or international associations of cities. Multilevel governance in this field is characterized by processes of information exchange and vertical and horizontal policy transfers, by the 'uploading' of local policies to international arenas and 'downloading' ideas and recommendations from these arenas to local governments. City governments in particular serve as places of experimental policy, and transnational arenas as processes of critical review, comparative evaluation and mutual learning. This rather loose linkage of local and international governance and the opportunities to shape policies in different arenas avoided tensions between multilevel interaction and local democracy, because the former neither constrained the competences nor determined the politics of elected city councils. Nonetheless, communicative multilevel interactions have evidently contributed no less to policy innovation than governance in hierarchy, that is, legislation or climate programmes of national governments.

Energy transition has been coordinated in different processes of multilevel governance. Aiming at a significant reduction of emissions causing global warming and climate change, it requires that national, regional and local governments effectively harmonize their policies. Conflicts of interests among different branches of industry, energy providers and consumers, territorial variations of energy systems, and the challenges of transition and party competition within governments complicate multilevel governance. In order to transform an energy system, mutual interference between processes of coordination and democratic politics needs to be managed. This was apparently possible in Denmark, where policy innovation in local governments induced the central government to change its course of energy policy and to respond with regulation and incentives supporting renewable energy. Policy coordination was not formally institutionalized but established interaction between the Danish government and local government associations contributed to bring into line the new policies of central and local energy policy. The processes of the consensus democracy helped to stabilize the new path of energy policy, even after citizen protests and a change in government boosted opposition. Thus, cooperative intergovernmental policymaking, 'public-private' negotiations between governments, industry, unions and civil society organizations, and negotiations between parties in parliament or city councils opened ways to manage the multidimensional conflicts in a highly flexible, multilevel governance regime. 
In Canada, energy policy has been divided and multilevel coordination remained weak for a long time because, within governments, competitive politics prevailed. As the provinces exploit different energy sources, the policies of the 'carbon provinces' diverge substantially from those of the 'hydro provinces' (Macdonald 2020). Lacking appropriate direction of the conservative federal government, some provinces engaged in energy transition, but these policies had neither significant effects on other provinces nor was there policy stability in the majoritarian democracy of the provinces. When after 2015 the federal government revived intergovernmental coordination after a decade of disengagement, it achieved an agreement, but some provinces refused to comply with important elements. The political process in a Westminster model of a parliamentary system concentrates power in the executives. With its support of a majority in parliament, an executive can change policies within its jurisdiction. But executives are also committed to their party in parliament, and in intergovernmental negotiations they have to defend their policy in bargaining processes. This explains why intergovernmental relations are hardly institutionalized in Canada (Bolleyer 2009), and why agreements can be innovative but never guarantee a continuous implementation. Multilevel governance is highly flexible but difficult to control.

In Germany, intergovernmental negotiations and parliamentary democracy constitute a rather rigid system of multilevel governance. However, processes in energy policy have been characterized by considerable dynamics. One reason was that power over energy is more centralized than in Denmark or Canada. Moreover, the federal parliament passed legislation to promote renewable energy and to phase out nuclear power by avoiding joint-decision making with the Länder governments. In negotiations within the federal coalition government and in public-private negotiations, the federal government initiated the transition towards energy generation based on renewable sources. This policy was clearly innovative and transformed the old policy regime. While Canada lacked stable cooperation between the federal and provincial governments and between the provinces to manage conflicts of interests, the German joint-decision system was weakened by centralization and unresolved conflicts among Länder governments. Federal and Länder policies have been coordinated in informal consultation among specialized administration and external experts, and binding decisions result from cooperation in the shadow of hierarchy. In these processes, energy transition continues by gradual change.

Politics of fiscal equalization represents a purely redistributive policy and concerns resources of governments. It is unique as de facto it requires joint decisions regardless of the division of power in general. Federal legislation regularly ratifies intergovernmental agreements negotiated by the federal and all regional governments. As the German case demonstrates, bargaining among executives makes significant policy change next to impossible. The 
Länder ministers, aware that they all have to justify the outcome in their parliament and in public, formed a status quo-oriented policy coalition against the federal government. In other federations we should expect the same bargaining behaviour of executives negotiating on fiscal equalization. However, if the policy process is differentiated in functional and temporal terms, innovative solutions of conflicts can be achieved. Differentiating an arena where experts meet from the arena of negotiations among political executives is one important condition. Another is the separation of decisions on the funds available, on the rules of redistribution of the funds, and on the application of these rules to determine the shares of each government. Arena and process differentiation, in combination with negotiations in the shadow of an obligatory referendum, explains the 2008 reform in Switzerland. In Australia, the substantial reform of the equalization funds and the later revision of the grants system was also elaborated in political and administrative negotiations, but more important was the implementation of fiscal equalization by an independent commission. In addition, the distribution of federal grants based on bilateral contracts between federal ministries and state governments and performance evaluations encouraged problem-oriented cooperation. In a way differing from the Swiss case, this multilevel governance process separated decisions on principles and rules from decisions determining the particular shares of each government. This way, communicative interaction was encouraged and defended against strategic bargaining and party competition in ratification within a loosely coupled arrangement of processes.

These cases support the theoretical assumption that structural differentiation of multilevel governance opens opportunities for policy innovation. Under the condition of sufficient institutional flexibility, actors can shape processes so that they can profit from the innovation potential of communicative interaction, use strategic action to promote the implementation of innovations, and nonetheless conform to institutional rules in order to legitimize new policies. The probability of innovative policies increases if these different processes are linked in a sequence, which first allows ideas of policy paradigms to materialize, which then sets a frame for strategic policymaking to substantiate a new policy. This way multilevel governance can make policy change possible against all odds of multidimensional conflicts and institutional complexity.

\section{CONCLUSION}

The rise of multilevel governance reflects the increasing complexity of problems in contemporary societies. In consequence, various conflicts afflict policymaking in multilevel governance. The functional division of power increases interdependence, whereas representatives of governments, who are involved in multilevel governance, defend their autonomy, in democracies no 
less than in autocracies. Therefore, the interplay of multilevel and domestic politics causes tensions, which can only be managed in a highly flexible institutionalization of multilevel governance.

Under these conditions, policy innovation depends on processes opening ways to evade the inherent constraints in multilevel governance. Separate but connected processes can be arranged in the multiple arenas that result from a division of power between levels and a differentiation of patterns of interactions into those involving executives, specialists in administration, members of political parties, parliamentarians, or private interest organizations. Depending on the particular actor constellation, some processes might enable problem-oriented communicative interactions (policy discourses), others are designed to cope with conflicts in bargaining processes or mutual adjustment in competitive relations, and, finally, decisions on policy proposals are taken in formal proceedings. The differentiation of processes allows a sequential coping with issues, such as principles and allocation rules in redistributive policies or standards and legal rules in regulative policies, but also increases feedback effects between sequences. The diversity of arenas with different actor constellations corresponds with a diversity of framing of policies in different processes. They can be more politically or expert oriented, more influenced by territorial conflicts or determined by party competition, and geared more towards generating ideas and testing policies in experiments or making binding and legitimate decisions.

Against common knowledge but also many, if not most, theoretical expectations, the complexity of structures and processes facilitates policy change and innovation. Of course, such complexity can also cause turbulence, and policymakers can lose control over dynamics of governance. Yet complexity itself is not the cause of deadlocks, impasses or 'bad deals'. Rather, it is more likely that central authorities, sovereign parliaments, powerful leaders of governments or bureaucrats cause deadlocks or only gradually modify established policies by their efforts to maintain control. 